\title{
Reassessing the spatial relationship between sponges and macroalgae in sublittoral rocky bottoms: a descriptive approach
}

\begin{abstract}
Because sublittoral sponges of temperate areas are usually more abundant at sites with low algal abundance, there is the widespread notion that macroalgae out-compete and displace sponges to habitats less suitable for algal proliferation. In this study, based on 292 sampling quadrats, we collected a total of $87 \mathrm{dem}-$ osponge species and examined the level at which sponge distribution pairs with a variety of alga-dominated and animal-dominated habitats occurring in three zones located across a marked in-bay/out-bay environmental gradient. We found significant differences in sponge biomass, richness and diversity between the 18 habitats considered in the three zones, with abundance, richness and diversity being significantly higher in caves, vertical surfaces and overhangs out of the bay than in the remaining habitats. The cluster analysis and the unconstrained ordination consistently reflected the inbay/out-bay environmental gradient. These analyses also revealed that the taxonomic distribution of sponge abundance is independent of the algal occurrence in the habitat, being more related to between-zone differences than to between-habitat differences. This trend was corroborated when the role of depth, algal abundance and substratum inclination in explaining total sponge
\end{abstract}

Communicated by H.-D. Franke

I. Preciado $(\bowtie)$

Instituto Español de Oceanografía (IEO),

Promontorio de San Martín s/n, 240,

39080 Santander, Spain

E-mail: ipreciado@st.ieo.es

Tel.: + 34-942-291060

Fax: + 34-942-275072

M. Maldonado

Department of Aquatic Ecology,

Centro de Estudios Avanzados de Blanes (CSIC),

Acceso Cala St. Francesc 14,

17300 Blanes, Girona, Spain

E-mail: maldonado@ceab.csic.es

Tel.: + 34-972-336101

Fax: + 34-972-337806 abundance and diversity was examined by canonical correspondence analysis, regression analysis and mean comparisons. These analyses pointed to substratum inclination, rather than to algal abundance, as the factor explaining most variation in distribution of sponge abundance. These results, when discussed in the context provided by the outcome of other studies concerned with the spatial distribution of the sessile benthos in rocky temperate communities, strongly suggest a need to reexamine the idea that spatial distribution of sublittoral sponges largely results from competition with macroalgae.

Keywords Macroalgae Rocky bottom - Spatial competition - Sponge distribution - Sublittoral ecology

\section{Introduction}

In temperate seas, sublittoral rocky communities are usually defined by their macroalgal composition (e.g., Pèrés and Picard 1964; Ballesteros 1989; Hiscock 1991; Castric-Fey et al. 2001). Nevertheless, it is often reported that sponges are also relevant members of these communities, occurring in both well-lit macroalga-dominated habitats (Laubenfels 1950; Sarà and Vacelet 1973) and shaded, alga-impoverished habitats (e.g., Sará and Vacelet 1973; Vacelet 1976; Bibiloni et al. 1989; Bell and Barnes 2002). Because sponges are usually more abundant in shaded than well-illuminated habitats, there is the widespread notion that algae usually out-compete sponges (e.g., Witman and Sebens 1990; Bell and Barnes 2000a, 2002) and displace them to habitats characterized by low irradiance, in which algal growth is limited (e.g., Vacelet 1976; Harmelin 1985; Rützler et al. 2000). Nevertheless, shaded habitats, such as vertical walls, overhangs, cracks, cave entrances, and similar ones, are also protected from UV radiation and silt, unfavorable factors for growth and survival of most sponges (e.g., Kitching et al. 1934; Hartnoll 1983; Sarà and Vacelet 
1973; Jokiel 1980; Maldonado and Uriz 1999). Therefore, other environmental effects may be confounded with algal competition in explaining high abundance of sponges in shaded habitats. Indeed, the level at which the environmental forces structuring macroalgal communities are responsible for the spatial distribution of sponges in sublittoral bottoms remains unclear. To our knowledge, the level of global matching between the distribution of the sponge fauna and standard macroalga-defined communities has been investigated in just one previous semi-quantitative attempt, which was based on Mediterranean assemblages (Uriz et al. 1992).

Herein we have approached this issue by quantitatively examining patterns of spatial distribution of demosponges in a variety of Atlantic rocky-bottom habitats within three sampling zones located along a sharp in-bay/out-bay environmental gradient. Specifically, we assessed the relevance of spatial scale (habitat versus zone level) on sponge distribution by examining differences in sponge fauna between similar habitats from different zones, and between different habitats within the same zone. Finally, we investigated the role of three major environmental factors (i.e., depth, algal abundance, and substratum inclination) in explaining sponge abundance.

\section{Materials and methods}

\section{Sampling}

We sampled three zones, Horadada Island (HI), Peninsula of Magdalena (MP), and Mouro Island (MI), respectively located in, at the entrance, and out of the Bay of Santander (North Atlantic coast of Spain; Fig. 1). The rocky bottom at HI consists mostly of subhorizontal surfaces sheltered from direct wave action but affected by strong tidal currents (Castillejo et al. 1984), intense sedimentation, and occasional burial by

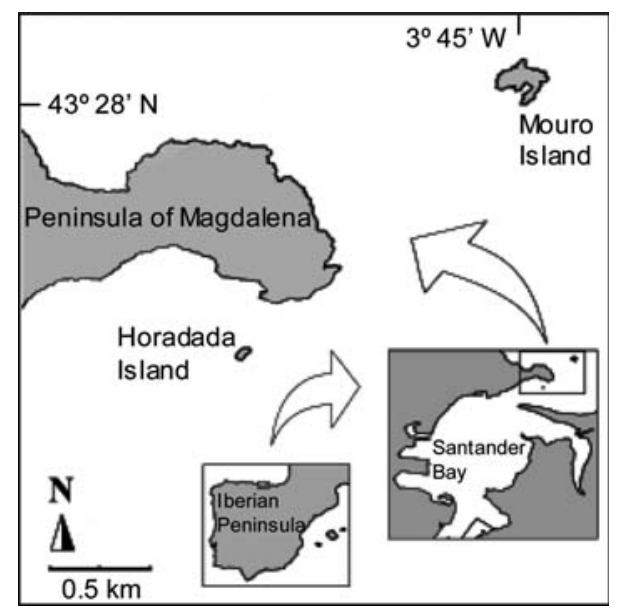

Fig. 1 Map of Santander Bay (Cantabrian Sea, North Atlantic coast of Spain) showing the three sampling zones: Horadada Island $(H I)$, Peninsula of Magdalena $(M P)$, and Mouro Island $(M I)$ sand from the adjacent soft bottoms. Unlike HI, MP and MI are highly exposed to wave action. At MP, the bottom is a large, relatively smooth rocky platform with a moderate slope towards offshore. At MI, the sublittoral landscape is dominated by large vertical walls forming an intricate system of narrow channels.

Most macrobenthic communities in the study zone, which are well known from previous studies, are defined in terms of algal abundance (García-Castrillo et al. 2000a; Puente 2000). There are three communities of large macroalgae, namely Laminaria ochroleuca, Gelidium sesquipedale, and Cystoseira baccata. There are also four communities dominated by mid-sized algae: an Asparagopsis armata community; a Codium tomentosum community; a community co-dominated by Dictyota dichotoma and Dictyopteris polypodioides; and a community co-dominated by Pterosiphonia complanata and Calliblepharis ciliata. Small-sized algae dominate two communities: Mesophyllum sp. and Aglaothamnion sp. An animal-dominated community, Anemonia viridis, also occurs in the studied zones.

Sampling was conducted by scuba diving between 0 and $20 \mathrm{~m}$ depth, excluding the intertidal zone, which is virtually deprived of sponges. We scraped 292 random quadrats, collecting all sponges and macroalgae. Quadrats measured $625 \mathrm{~cm}^{2}$, except for those $(n=44)$ falling within the Laminaria ochroleuca community, which were $2,500 \mathrm{~cm}^{2}$ because of the large algal size. As we sampled quadrats of two different sizes, algal and sponge abundance values were referred to per square meter for further statistical analyses. All collected organisms were fixed in $10 \%$ formalin, stored in $70 \%$ ethanol, and identified to species level in the laboratory following standard methods (Puente 2000; Preciado 2002).

Demosponge distribution patterns across sublittoral habitats

To assess the level of matching between algal and sponge distribution patterns, we considered a total of nine sublittoral "habitats", as explained below. Because algae with similar sizes and growth forms are assumed to exert similar pressure in spatial competition, we pooled in the analyses communities dominated by algae with similar growth habit and size for the sake of simplification. Therefore, communities of Cystoseira baccata and Gelidium sesquipedale were grouped into the large-size-algae (LSA) community-group. The large alga Laminaria ochroleuca (LAM) was regarded separately, because its peculiar rhizoids provide a particularly suitable habitat for sponges (Pansini 1987; Templado et al. 1993; GarcíaCastrillo et al. 2000b). Similarly, we grouped communities of Asparagopsis armata, Codium tomentosum, Pterosiphonia complanata, Calliblepharis ciliata, Dictyota dichotoma, and Dictyopteris polypodioides into a mid-size-algae (MSA) assemblage. We considered communities of Mesophyllum sp. (MES) and Aglaothamnion sp. (AGL) separately, as well as the Anemonia viridis 
(ANE) community. In addition, we considered three habitats dominated by filter-feeding invertebrates (sponges, bryozoans, ascidians) with scarce or null algal presence, i.e. walls and vertical surfaces (WVS), overhangs $(\mathrm{OVH})$, and cave entrances (CAV). After these considerations, we obtained a total of nine distribution units (hereafter referred to as "habitats"), five algadominated and four animal-dominated. Six out of the nine defined habitats were represented at $\mathrm{HI}$, five at MP, and seven at MI, resulting in a total of 18 groups from the "habitat-zone" interaction.

We examined differences in total sponge abundance (average dry weight $\mathrm{m}^{-2}$ ), species richness (average species number per quadrat), and Shannon-Wiener diversity (species dry weight per quadrat) between the three studied zones, i.e., HI $(n=25)$, MP $(n=16)$, and MI $(n=255)$, using a Kruskal-Wallis one-way ANOVA on ranks. When significant differences were detected, we ran pairwise "a posteriori" Dunn's tests to identify the groups responsible for such differences. Note that to capture $95 \%$ of algal-sponge diversity, the higher complexity of communities at MI required higher sampling effort than that at HI and MP.

We also examined differences in total sponge abundance (average dry weight $\mathrm{m}^{-2}$ ), species richness (average species number $\mathrm{m}^{-2}$ ), and Shannon-Wiener diversity (species dry weight $\mathrm{m}^{-2}$ ) per quadrat between the different habitats of the three studied zones. Because six out of the 18 resulting habitat-zone groups were under-sampled $(n=2)$, the statistical analysis involved just 12 groups. Differences between "habitat-zone" groups were tested using a one-way ANOVA on rank-transformed data that met normality and homoscedasticity tests. When significant differences were detected, we ran pairwise "a posteriori" Student-Newman-Keuls (SNK) tests to identify the groups responsible for the differences.

Quantitative differences in the taxonomic distribution of sponges collected in the 18 habitat-zone groups were addressed by cluster analysis and unconstrained correspondence. After removing sponge species which were only present in one habitat-zone group, and "habitatzone" groups containing either no sponges or just one species, we submitted to analysis a matrix containing 16 habitat-zone groups per 73 sponge species. To cluster habitat-zone groups on the basis of the sponge fauna, we first calculated Bray-Curtis pairwise faunal dissimilarities between groups using fourth-root transformed sponge abundances, then processed the distance matrix using the UPGMA algorithm. We also ran SIMPER analyses to identify the main sponge species responsible for the major dissimilarities in the tree. Finally, we examined the explainable variation in sponge fauna within the "species per habitat-zone groups" matrix by unconstrained correspondence analysis (CA). Because uneven abundance distribution and rare taxa may distort ordination scores, we log-transformed abundance data and down-weighted rare species (i.e., with low abundances) in the analysis, using the option available in the CANOCO 4.0 software.
Effect of depth, algal abundance, and substratum inclination on sponge distribution

To assess the amount of variation in sponge abundances per habitat-zone group related to three environmental variables presumed important in habitat characterization (i.e., depth, algal abundance, substratum inclination), we used canonical correspondence analysis (CCA). Depth and algal abundance were considered as continuous variables, respectively recorded as depth of sampling quadrat and wet weight of total algal content scraped from each quadrat and referred to per square meter. Substratum inclination was recorded as a semiquantitative variable, indicating the approximate angle of the seafloor at each quadrat relative to the horizontal. Horizontal and sub-horizontal surfaces, represented by substrata angling from $0^{\circ}$ to $45^{\circ}$, were recorded in the matrix by the median angle $22^{\circ}$. Vertical and sub-vertical walls, represented by substrata angling from $46^{\circ}$ to $90^{\circ}$, were recorded as $68^{\circ}$; overhangs, represented by substrata angling from $91^{\circ}$ to $135^{\circ}$, were recorded as $113^{\circ}$. Ceilings of small caves and cracks, represented by substrata angling from $136^{\circ}$ to $180^{\circ}$, were recorded as $158^{\circ}$. Unlike in the CA, CCA calculations were based on log-transformed abundance of all species collected, but down-weighting rare species. This allowed us to consider in the analysis as much potential variation in sponge abundance distribution as possible. The statistical significance of the first and all canonical axes together was tested by the Monte-Carlo tests using 999 permutations under the reduced model. CCA results were presented graphically in a bidimensional ordination diagram generated by biplot scaling focussed on inter-species distances, in which species are represented by points and environmental variables by vectors.

Finally, we ran separate analyses to investigate the relationships between each of the environmental factors (i.e., depth, algal abundance, and substratum inclination) and sponge abundance and diversity. We examined the level of association of total sponge abundance and sponge diversity per quadrat with depth and algal abundance per quadrat using Pearson correlation ( $n=292$ in all cases). We also examined differences in sponge abundance and diversity per quadrat as a function of substratum inclination, i.e., horizontal surfaces $(n=154)$, vertical surfaces $(n=95)$, overhangs $(n=30)$, and ceilings $(n=13)$, using Kruskal-Wallis one-way ANOVA on ranks. "A posteriori" Dunn's tests were used to identify the groups responsible for the significant differences, if any.

\section{Results}

Demosponge distribution patterns across sublittoral habitats

A total of 257 out of 292 quadrats (88\%) contained demosponges, with representatives of 85 species and nine taxonomic orders (Table 1). The orders Poecilo- 
Table 1 Demosponges collected in the study listed by decreasing order of abundance

\begin{tabular}{|c|c|c|c|c|}
\hline No. & Order & Species & $\mathrm{B}$ & Percentage \\
\hline 2 & DIC & Spongia officinalis & $8.74(57.5)$ & 18.9 \\
\hline 4 & AST & Stelletta grubei & $5.38(52.3)$ & 13.5 \\
\hline 5 & $\mathrm{DIC}$ & Dysidea avara & $4.46(14.6)$ & 29.7 \\
\hline 6 & HAL & Hymeniacidon sanguinea & $3.97(13.9)$ & 18.2 \\
\hline 7 & AST & Stelletta simplicissima & $3.31(15.3)$ & 12.5 \\
\hline 10 & AST & Erylus discophorus & $2.04(10.5)$ & 13.8 \\
\hline 11 & HAL & Halichondria aurantiaca & $1.89(20.5)$ & 1.6 \\
\hline 12 & POE & Myxilla rosacea & $1.84(11.6)$ & 11.4 \\
\hline 13 & HAD & Cliona celata & $1.65(11.4)$ & 5.4 \\
\hline 14 & DIC & Spongia agaricina & $1.61(18.1)$ & 1.0 \\
\hline 15 & HPL & Haliclona mamillata & $1.34(9.3)$ & 34.1 \\
\hline 21 & $\mathrm{DIC}$ & Sarcotragus spinosulus & $0.51(7.6)$ & 0.7 \\
\hline 22 & HAD & Adreus fascicularis & $0.50(8.7)$ & 0.3 \\
\hline 23 & POE & Tedania anhelans & $0.44(3.1)$ & 14.2 \\
\hline 24 & AST & Stelletta hispida & $0.43(3.0)$ & 3.4 \\
\hline 25 & HPL & Haliclona simulans & $0.40(1.9)$ & 12.8 \\
\hline 26 & HAL & Halichondria panicea & $0.37(1.9)$ & 17.2 \\
\hline 27 & HAD & Suberites carnosus & $0.37(3.6)$ & 1.7 \\
\hline 28 & AST & Stelletta dorsigera & $0.36(2.8)$ & 3.0 \\
\hline 29 & AST & Pachymatisma johnstoni & $0.25(3.1)$ & 0.7 \\
\hline 30 & POE & Phorbas fictitius & $0.24(1.4)$ & 16.9 \\
\hline 31 & HPL & Haliclona angulata & $0.22(1.1)$ & 10.8 \\
\hline 32 & POE & Myxilla macrosigma & $0.20(1.2)$ & 6.7 \\
\hline 33 & $\mathrm{HOM}$ & Corticium candelabrum & $0.16(2.0)$ & 2.0 \\
\hline 43 & HAD & Pseudosuberites sulphurea & $0.07(0.8)$ & 1.7 \\
\hline 44 & HPL & Haliclona fibulata & $0.07(0.4)$ & 9.8 \\
\hline 45 & POE & Phorbas plumosum & $0.06(0.6)$ & 5.4 \\
\hline 46 & HAL & Axinella verrucosa & $0.06(0.7)$ & 2.3 \\
\hline 47 & POE & Antho inconstans & $0.06(0.9)$ & 0.7 \\
\hline 48 & POE & Phorbas dives & $0.06(0.5)$ & 4.0 \\
\hline 49 & HAD & Polymastia mamillaris & $0.05(0.5)$ & 3.4 \\
\hline 50 & POE & Myxilla iotrochotina & $0.05(0.5)$ & 3.0 \\
\hline 51 & HOM & Plakortis simplex & $0.05(0.4)$ & 2.4 \\
\hline 52 & HAL & Axinella damicornis & $0.05(0.3)$ & 5.4 \\
\hline 53 & HAD & Protosuberites epiphytum & $0.04(0.6)$ & 1.7 \\
\hline 54 & HPL & Haliclona subtilis ${ }^{\top}$ & $0.04(0.3)$ & 8.1 \\
\hline 55 & POE & Hemimycale columella & $0.03(0.6)$ & 0.7 \\
\hline 56 & POE & Clathria depressa & $0.03(0.3)$ & 3.4 \\
\hline 57 & VER & Aplysina cavernicola & $0.03(0.3)$ & 3.4 \\
\hline 58 & POE & Hymedesmia dujardini & $0.03(0.4)$ & 3.4 \\
\hline 59 & HPL & Haliclona vagabunda & $0.03(0.3)$ & 1.0 \\
\hline 60 & POE & Microciona atrasanguinea & $0.03(0.4)$ & 1.7 \\
\hline 61 & HPL & Haliclona mediterranea & $0.02(0.2)$ & 2.4 \\
\hline 62 & DEN & Spongionella pulchella & $0.02(0.2)$ & 2.7 \\
\hline 63 & POE & Hymedesmia pansa & $0.02(0.2)$ & 1.7 \\
\hline 64 & HOM & Oscarella lobularis & $0.02(0.2)$ & 2.0 \\
\hline 65 & HPL & Callyspongia simplex & $0.01(0.2)$ & 0.3 \\
\hline 66 & POE & Crella elegans & $0.01(0.1)$ & 3.7 \\
\hline 67 & HPL & Oceanapia isodictyiformis & $0.01(0.1)$ & 3.0 \\
\hline 68 & DEN & Aplysilla sulfurea & $0.01(0.1)$ & 2.7 \\
\hline
\end{tabular}


Table 1 (Contd.)

\begin{tabular}{|c|c|c|c|c|}
\hline No. & Order & Species & $\mathrm{B}$ & Percentage \\
\hline 70 & HPL & Haliclona crassa & $0.00(0.1)$ & 1.7 \\
\hline 72 & HAL & Dictyonella incisa & $0.00(0.1)$ & 0.3 \\
\hline 73 & POE & Crella fusifera & $0.00(0.1)$ & 0.7 \\
\hline 74 & HAL & Axinella polypoides & $0.00(0.0)$ & 0.3 \\
\hline 75 & POE & Raspailia pumila & $0.00(0.0)$ & 1.3 \\
\hline 78 & POE & Microciona armata & $0.00(0.0)$ & 0.7 \\
\hline 79 & HOM & Plakina monolopha & $0.00(0.0)$ & 0.7 \\
\hline 80 & POE & Eurypon lacazei & $0.00(0.0)$ & 0.3 \\
\hline 81 & POE & Phorbas coriaceus & $0.00(0.0)$ & 2.0 \\
\hline 82 & POE & Amphilectus fucorum & $0.00(0.0)$ & 0.7 \\
\hline 83 & HAL & Bubaris vermiculata & $0.00(0.0)$ & 0.3 \\
\hline
\end{tabular}

No. rank value of abundance; $B$ average dry weight $\left(\mathrm{g} \mathrm{m}^{-2}\right)$ and standard deviation (in brackets); Percentage frequency of occurrence in sampling quadrats. Acronyms for taxonomic orders are as follows: $A S T$ Astrophorida, $C H O$ Chondrosida, DEN Dendro-

sclerida (30 species) and Haplosclerida (12 species) were best represented by species number, but Dictyoceratida $(227.56 \mathrm{~g})$ and Astrophorida (153.26 g) were the most important in terms of biomass. The dictyoceratids Ircinia variabilis $\left(12.55 \mathrm{~g} \mathrm{~m}^{-2}\right)$ and Spongia officinalis $\left(8.74 \mathrm{~g} \mathrm{~m}^{-2}\right)$, along with the astrophorid Geodia cydonium $\left(5.76 \mathrm{~g} \mathrm{~m}^{-2}\right)$, were the most abundant species by biomass. By frequency of occurrence in sampling quadrats, the most common species were Haliclona mamillata (34\%), Dysidea avara (30\%), Hyrtios collectrix (27\%), Geodia cydonium (23\%) and Spongia officinalis $(19 \%)$. It is noteworthy that some species that appeared in very few quadrats showed high biomass, such as Spongia agaricina, occurring in three sample quadrats only but averaging $158.72 \mathrm{~g} \mathrm{~m}^{-2}$, and Adreus fascicularis and Halichondria aurantiaca, occurring in just one quadrat each but reaching $149.49 \mathrm{~g} \mathrm{~m}^{-2}$ and $111.76 \mathrm{~g} \mathrm{~m}^{-2}$, respectively.

We did not find any significant between-zone differences in sponge biomass (Fig. 2a), but we did find differences in sponge species richness (Fig. 2b) and diversity (Fig. 2c), with richness and diversity increasing from the bay zone (HI) to the offshore zone (MI). We also found significant differences in sponge biomass (Fig. 3a), richness (Fig. 3b), and diversity (Fig. 3c) between the different sublittoral habitats considered in the three zones studied. According to the "a posteriori" tests, sponge abundance, richness and diversity were significantly higher in the caves, vertical surfaces, and overhangs of Mouro Island than in the remaining habitat-zone groups.

The cluster analysis of faunal affinities between habitat-zone groups (Fig. 4) depicted two major blocks (mean dissimilarity $=85.03 \%$ ): one consisting of habitats exclusively at the Horadada Island (group I); the other ceratida, DIC Dictyoceratida, $H A D$ Hadromerida, $H A L$ Halichondrida, HOM Homosclerophorida, HPL Haplosclerida, POE Poecilosclerida, VER Verongida
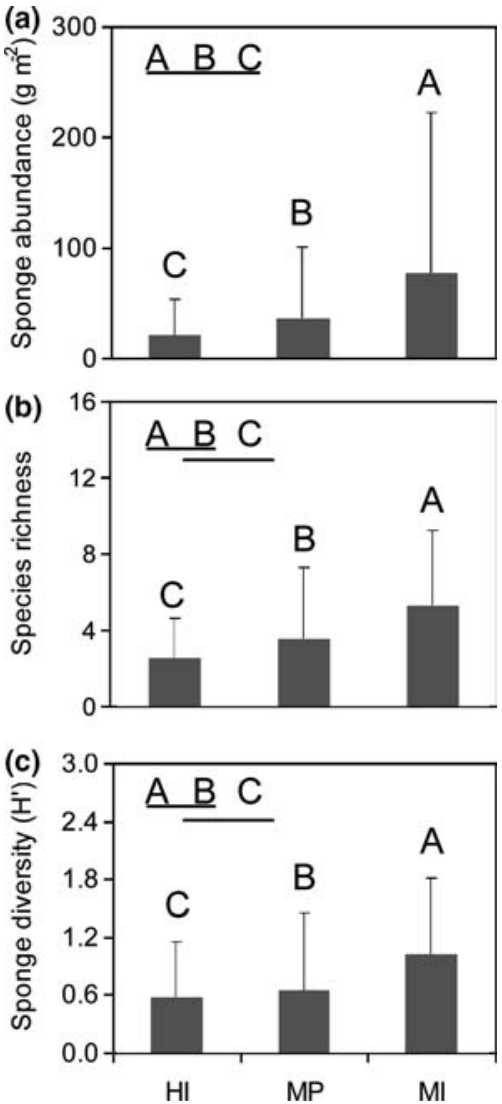

Fig. 2 a Total sponge abundance $\left(\mathrm{g} \mathrm{m}^{-2}\right)$, b species richness, and c diversity $\left(H^{\prime}\right)$ per quadrat at Horadada Island $(H I)$, Peninsula of Magdalena $(M P)$, and Mouro Island $(M I)$. Bars represent mean ( $\pm \mathrm{SD})$ values. Uppercase letters $(A-C)$ refer to mean values arranged in decreasing order. Groups of underlined letters indicate non-significant differences between pairs of means according to "a posteriori" Dunn's tests following a significant Kruskal-Wallis ANOVA on ranks 

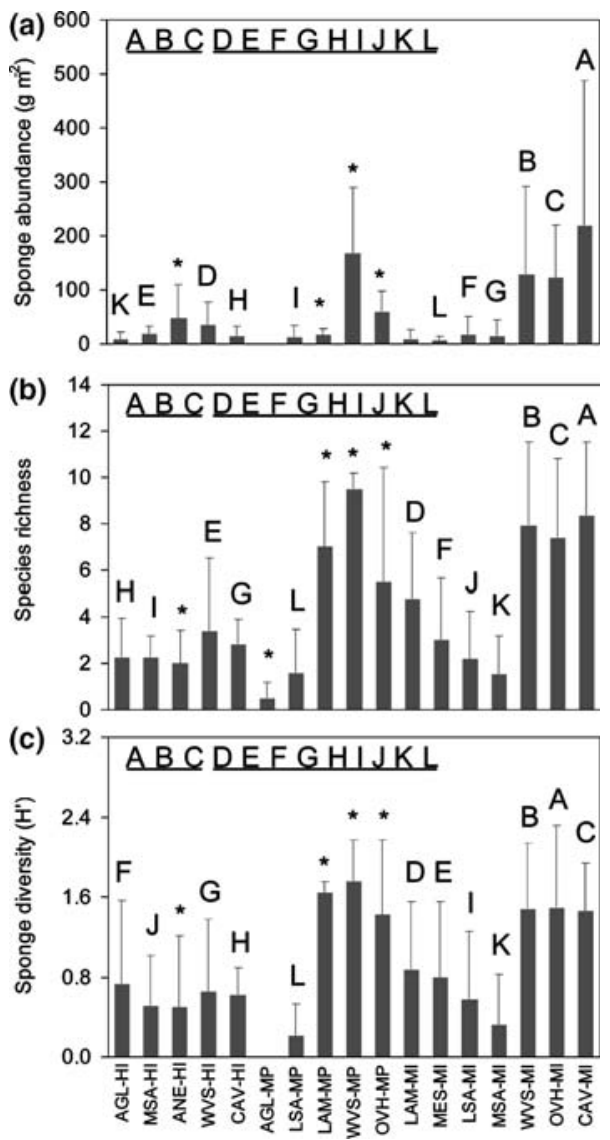

Fig. 3 a Total sponge abundance $\left(\mathrm{g} \mathrm{m}^{-2}\right)$, b species richness, and c diversity $\left(H^{\prime}\right)$ per quadrat at each habitat-zone assemblage (see acronyms below). Bars represent mean ( \pm SD) values. Uppercase letters $(A-L)$ refer to mean values arranged in decreasing order. Groups of underlined letters indicate non-significant differences between pairs of means, according to "a posteriori" SNK tests following a significant one-way ANOVA. Asterisks indicate undersampled communities that were not considered in the statistical analysis. Acronyms for habitat-zone assemblages are a combination of two terms: one for zone (HI Horadada Island, $M P$ Peninsula of Magdalena, MI Mouro Island), one for habitat or community (AGL Aglaothamnion sp.; ANE Anemonia viridis; $C A V$ cave entrance; LAM Laminaria ochroleuca; $L S A$ communities of large-size algae; MES Mesophyllum sp.; MSA communities of medium-size algae; $O V H$ overhangs; $W V S$ walls and other vertical surfaces) consisting of a mix of habitats from the Peninsula of Magdalena and Mouro Island (group II). The SIMPER analysis of dissimilarity between both major groups showed that the species Stelletta simplicissima, Ciocalypta penicillus, and Cliona celata contributed most to the dissimilarity (Table 2). Within group II, there were two subgroups (mean dissimilarity $=76.89 \%$ ). One is exclusively formed by the large-size-algae assemblage and the Laminaria ochroleuca community at the Peninsula of Magdalena (subgroup II.1); the other (subgroup II.2) consists of all habitats and communities of Mouro Island and those of the Peninsula of Magdalena that provide very suitable substrata for sponge growth (i.e., overhangs and rocky vertical surfaces). The SIMPER analysis revealed that Ircinia variabilis and Hymeniacidon sanguinea, both with high abundance at MI, and Stelletta simplicissima, with high abundance at MP, are the species contributing most to the dissimilarity of these two subgroups (Table 2). The global tree topology is highly consistent with the occurrence of a marked environmental gradient between Horadada Island (within Santander Bay) and Mouro Island (outside the bay), with Peninsula of Magdalena as a transition zone, though faunally closer to MI than to HI. In summary, the taxonomic distribution of sponge abundance appears to be more related to between-zone differences than to between-habitat differences, and is independent of the algal presence in the habitat.

This general pattern is corroborated by a correspondence analysis, the four first axes of which explain $50.2 \%$ of total faunal variation within the "species per habitat" matrix (Fig. 5). Axis 1 of the ordination diagram reflects a gradient in total sponge abundance per habitat-zone group, which also corresponds with the environmental gradient from the in-bay habitats of HI (with low total abundances) to the out-bay habitats of MI (with high total abundances and containing $70 \%$ of species). Therefore, distribution of habitat-zone groups on axis 1 is unrelated to the presence-absence of large, medium-sized, or small algae in the habitats. Axis 2 discriminates between habitats according to the "exclusiveness" of their fauna, depicting habitats characterized by high abundance of rare species in the matrix at ex-
Fig. 4 Tree of habitat-zone assemblages based on BrayCurtis dissimilarity of sponge abundance. For information on species responsible for the major nodes in the tree topology, see Table 2. Acronyms for habitat-zone assemblages are as given in the legend for Fig. 3

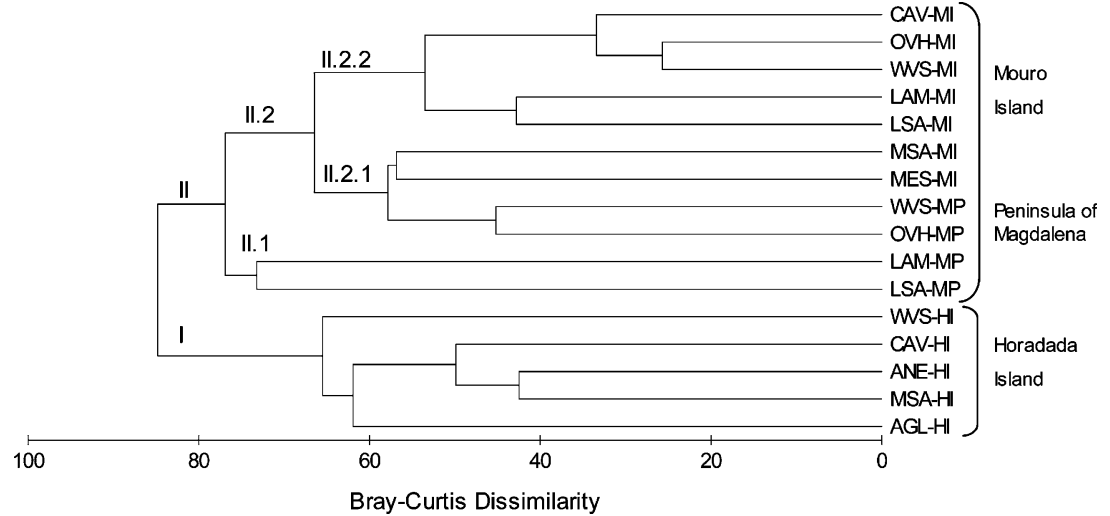


Table 2 Demosponges that contributed most to the dissimilarity between the groups resulting from the cluster analysis of habitat-zone units. $A B U$ average abundance in the cluster group; DIS mean dissimilarity; $D I S / S D$ mean dissimilarity-standard deviation ratio; $\% S P$ individual species contribution to total dissimilarity; \%CUM cumulative percentage of species contributions

\begin{tabular}{|c|c|c|c|c|c|c|}
\hline & $\mathrm{ABU}(\mathrm{I})$ & ABU (II) & DIS & $\mathrm{DIS} / \mathrm{SD}$ & $\% \mathrm{SP}$ & $\%$ CUM \\
\hline \multicolumn{7}{|l|}{ Groups I and II } \\
\hline S. simplicissima & 1.58 & 30.04 & 4.37 & 1.06 & 5.14 & 5.14 \\
\hline C. penicillus & 17.27 & 1.13 & 4.20 & 1.24 & 4.94 & 10.08 \\
\hline C. celata & 19.85 & 18.73 & 3.85 & 1.05 & 4.53 & 14.61 \\
\hline H. collectrix & 0.00 & 7.88 & 3.69 & 1.85 & 4.33 & 18.94 \\
\hline I. variabilis & 0.00 & 30.86 & 3.52 & 1.09 & 4.14 & 23.08 \\
\hline & ABU (II.1) & ABU (II.2) & & & & \\
\hline \multicolumn{7}{|c|}{ Groups II.1 and II.2 } \\
\hline I. variabilis & 0.00 & 37.72 & 4.01 & 1.47 & 5.21 & 5.21 \\
\hline H. sanguinea & 0.00 & 15.25 & 3.88 & 1.49 & 5.05 & 10.26 \\
\hline S. simplicissima & 27.01 & 30.71 & 3.33 & 1.29 & 4.34 & 14.60 \\
\hline C. celata & 0.00 & 22.89 & 2.98 & 1.10 & 3.88 & 18.47 \\
\hline S. officinalis & 0.00 & 23.18 & 2.75 & 1.65 & 3.57 & 22.04 \\
\hline & ABU (II.2.1) & ABU (II.2.2) & & & & \\
\hline \multicolumn{7}{|c|}{ Groups II.2.1 and II.2.2 } \\
\hline S. grubei & 8.82 & 46.54 & 2.34 & 1.80 & 3.48 & 3.48 \\
\hline G. cydonium & 0.00 & 16.36 & 2.21 & 7.42 & 3.28 & 6.77 \\
\hline I. variabilis & 18.15 & 53.38 & 1.95 & 1.51 & 2.90 & 9.67 \\
\hline T. anhelans & 0.88 & 25.17 & 1.80 & 1.08 & 2.67 & 12.34 \\
\hline S. hispida & 0.00 & 11.18 & 1.72 & 1.56 & 2.55 & 14.89 \\
\hline
\end{tabular}

treme positive or negative positions in the axis. For instance, the Aglaothamnion community at HI (Fig. 5a) takes maximum positive values in axis 2 because it contains maximum abundance of Protosuberites epiphytum and Phorbas plumosum (Fig. 5b), the abundances of which are very low in the other habitat-zone groups. Likewise, the Anemonia community takes extreme negative values (Fig. 5a) because it is characterized by high abundances of Ciocalypta penicillus (Fig. 5b), a species absent or represented at much lower abundance in other habitats. Axis 2 can be said to represent "taxonomic distinctiveness of habitat". Therefore, should algal abundance have a relevant role in explaining sponge distribution, we would expect unsuitable algal habitats (i.e., overhangs, rocky walls, cave entrances, etc.) to concentrate most sponges and to be clearly separated from suitable algal habitats. Such a pattern did not occur.

Effect of depth, algal abundance, and substratum inclination on sponge distribution

The first four axes of a CCA explained $39.2 \%$ of faunal variation in the "species per habitat-zone group" matrix, with axes 1 and 2 accounting for $12.1 \%$ and $8.1 \%$, respectively (Fig 6). Monte-Carlo tests indicated that both the first axis $(P=0.01)$ and all canonical axes together $(P=0.003)$ were significant. Therefore, the environmental variables under study are clearly responsible for at least some of the faunal variation. Axis 1 of the CCA, which shows moderate correlation with both depth $(r=-0.55)$ and substrate inclination $(r=-0.67)$, corroborated the major pattern in sponge distribution revealed by axis 1 of the unconstrained CA. That is, there is an increase in total sponge abundance-from right to left-across habitat-zone groups (Fig. 6a). This pattern is consistent with the bay-offshore environmental gradient, and also with an increase in depth and a shift in substrate inclination (dominance of horizontal versus vertical surfaces and overhangs). It is noteworthy that axis 2 , which correlates highly with algal abundance $(r=0.91)$, does not discriminate between algal-dominated and animal-dominated habitat-zone groups. Rather, axis 2 discriminates habitat-zone groups with high algal abundance and high sponge abundance from those with sponge species that are poorly represented in most other communities (i.e., taxonomic exclusiveness). Maximum positive values on axis 2 are for communities of large algae at Mouro Island (Cystoseira baccata, Gelidium sesquipedale), which, contrary to the general prediction of intense spatial competition, allow relatively important sponge populations to grow below their fronds (Fig. 6a). Some sponges, such as Hymedesmia dujardini, Tedania anhelans, Callyspongia simplex, Crella rosea, and Clathria depressa either show maximum abundance in these algal communities or are exclusive to them. Similarly, relatively high abundance of nearly exclusive sponges is also found on the rhizoids of Laminaria ochroleuca at MI (Fig. 6b).

When depth and algal abundance were plotted against sponge abundance and diversity (Fig. 7), we found that only algal biomass correlated negatively with sponge abundance and diversity (Figs. 7c,d). However, the strength of the association was extremely weak, with algal abundance reliably predicting sponge abundance and diversity in only about $4 \%$ of cases. Therefore, these results suggest again that, though macroalgae and sponges may often occupy disjunct habitats, such distribution is unlikely to be the result of sponges being outcompeted by macroalgae. There may be other confounding factors. Substrate inclination, which does not only affect exposure to light but also to sediment, may be one of the "hidden" factors. A Kruskal-Wallis 


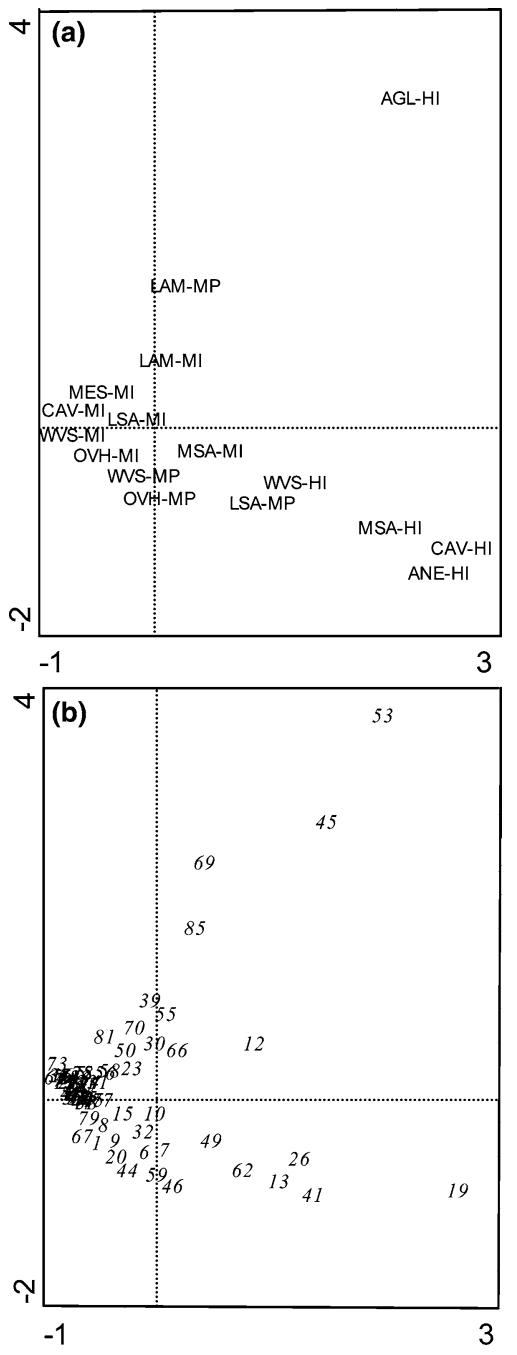

Fig. 5 Unconstrained CA showing the bi-dimensional ordination of a habitat-zone assemblages and $\mathbf{b}$ species. Habitat-zone assemblages are indicated by acronyms (as explained in Fig. 3) and demosponge species are represented by numbers (as explained in Table 1)

ANOVA and the "a posteriori" tests revealed that sponge abundance was substantially lower in horizontal surfaces, which are often alga-dominated, than in nonhorizontal, animal-dominated surfaces, irrespective of whether the non-horizontal surfaces are walls, overhangs, or cave ceilings (Fig. 8a). Interestingly, when differences in sponge diversity were examined (Fig. 8b), horizontal surfaces had significantly lower diversity values than vertical surfaces and overhangs, but similar ones to those of ceilings, which is the most unsuitable algal habitat.

\section{Discussion}

The results of this study strongly suggest that the structure of demosponge assemblages on rocky bottoms is largely determined by environmental factors other than algal abundances. Although it is well known that
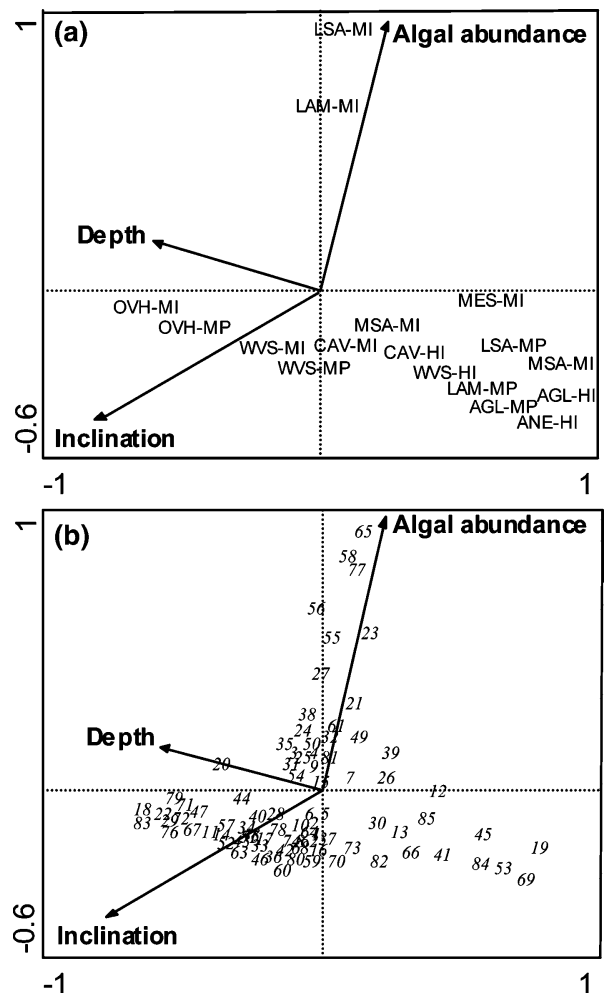

Fig. 6 CCA showing the bi-dimensional ordination of a habitatzone assemblages and $\mathbf{b}$ species. Superimposed vectors represent the environmental variables. Habitat-zone assemblages are indicated by acronyms (as explained in Fig. 3) and demosponge species are represented by numbers (as explained in Table 1)

algal abundance peaks in habitats where sponge abundance is low and vice-versa (e.g., Sará and Vacelet 1973), algal abundance per se does not appear to be the factor directly responsible for shifts in sponge abundance. Consistent with a previous study reporting a mismatch between the distribution of Mediterranean sponges and (a)

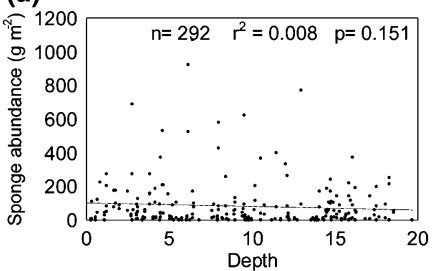

(c)

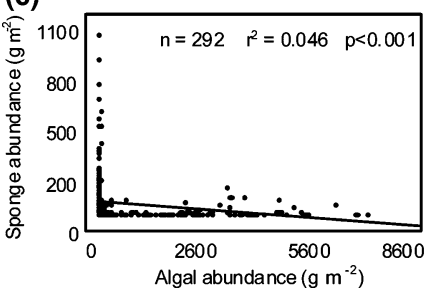

(b)

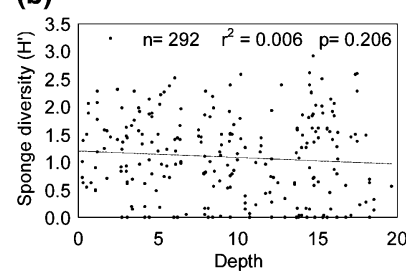

(d)

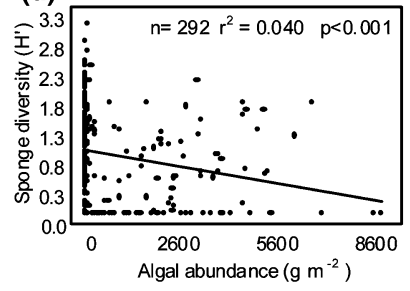

Fig. 7 Pearson correlation analyses examining variation in total sponge abundance (ODW $\mathrm{g} \mathrm{m}^{-2}$ ) and diversity $\left(H^{\prime}\right)$ per quadrat as a function of depth and algal abundance (WW $\mathrm{g} \mathrm{m}^{-2}$ ) 

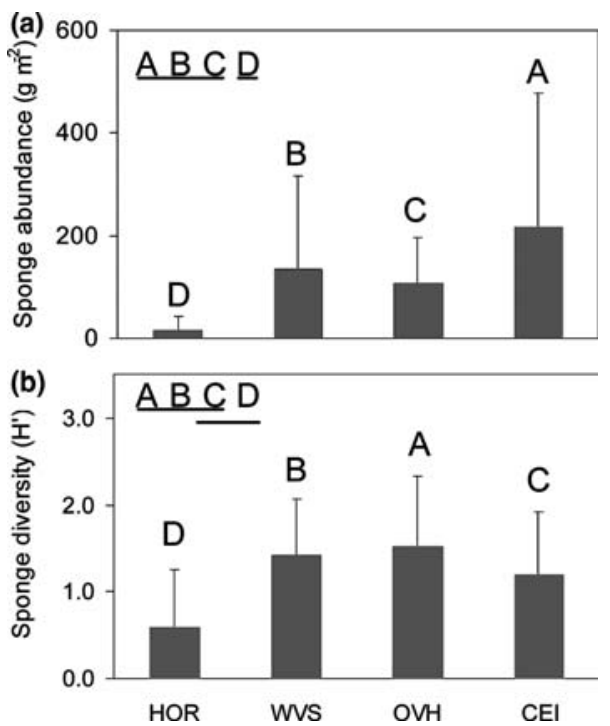

Fig. 8 a Mean $( \pm \mathrm{SD})$ sponge abundance $\left(\mathrm{g} \mathrm{m}^{-2}\right)$ and $\mathbf{b}$ diversity $\left(H^{\prime}\right)$ per quadrat as a function of semi-quantitative levels of substrate inclination (i.e., horizontal surfaces $H O R$, walls and vertical surfaces $W V S$, overhangs $O V H$, and ceilings $C E I$ ). Uppercase letters $(A-D)$ refer to mean values arranged in descending order. Groups of underlined letters indicate nonsignificant differences between pairs of means according to "a posteriori" Dunn's tests following a significant Kruskal-Wallis ANOVA on ranks

algae (Uriz et al. 1992), we have found no group of sponge species particularly associated with the presenceabsence of macroalgae. Rather, we have found that major patterns in sponge distribution are related to between-zone differences rather than to between-community differences. We have also found relatively important sponge occurrence in communities dominated by large algae such as Cystoseira baccata, Gelidium sesquipedale, and Laminaria ochroleuca. Indeed, the intricate rhizoid system of Laminaria ochroleuca appears to be a very suitable substratum for sponge growth, as previously reported by other studies (Pansini 1987; Templado et al. 1993; Maldonado and Uriz 1995).

Despite the fact that depth has been shown to play a role in structuring sponge communities (e.g., Witman and Sebens 1990; Alcolado 1979; Díaz et al. 1990; Schmahl 1990; Ghiold et al. 1994; Bell and Barnes 2000a, $2000 \mathrm{~b}$ ), in the narrow bathymetric range considered in this study, depth played a weak role in explaining sponge distribution. The "depth" effect on the sponge fauna was usually associated with in-bay/out-bay gradient effects, since bottoms within Santander Bay (HI) are slightly but consistently shallower than those out of the bay (MI). Unlike depth, differences in substratum inclination, i.e., horizontal versus non-horizontal surfaces, appear to strongly affect both algal and sponge abundances. Just because the negative effects of ultraviolet radiation (Jokiel 1980), silt (Kitching et al. 1934; Hartnoll 1983; Sarà and Vacelet 1973), and exposure to predators (Dunlap and Pawlik 1996) attenuate for sponges settled on rocky walls, overhangs, and ceilings, these habitats may develop rich sponge populations (e.g., Boury-Esnault 1971; Witman and Sebens 1990) by a process that, contrary to the general view, would be unrelated to the presence-absence of macroalgae. This view is also consistent with reports that sponge abundance at bathyal depths, where macroalgae do not occur, is markedly higher on vertical than horizontal surfaces (Maldonado and Young 1996). In summary, the results of this descriptive approach strongly suggest that the widespread idea that the spatial distribution of sublittoral sponges is largely determined by spatial competition with macroalgae should be carefully revised using manipulative approaches to elucidate under which circumstances competition, if any, is exerted.

Acknowledgements The authors are indebted to Dr. Gerardo García-Castrillo (ACEM) for his logistic and financial support through a grant from the Marcelino Botín Foundation, which made this research at Santander Bay possible. Manuscript elaboration also benefited from funds from the Spanish Government to M.M. (BMC2002-01228). The authors also thank the ACEM staff for their valuable help in sampling tasks, and Alberto Serrano for general support to I.P. and discussion on early drafts of this manuscript.

\section{References}

Alcolado PM (1979) Estructura ecológica de la comunidad de esponjas en un perfil costero de Cuba. Cienc Biol 3:105-127

Ballesteros E (1989) Els ecosystems bentònics. In: Folch R (ed) Sistemes naturals. Historia Natural dels Paisos Catalans. Enciclopedia Catalana SA, pp119-176

Bell JJ, Barnes DKA (2000a) A sponge diversity centre within a marine 'island'. Hydrobiologia 440:55-64

Bell JJ, Barnes DKA (2000b) The influences of the bathymetry and flow regime upon the morphology of sublittoral sponge communities. J Mar Biol Ass UK 80:707-718

Bell JJ, Barnes DKA (2002) The sponge community in a semisubmerged temperate sea-cave: density, diversity and richness. PSZN Mar Ecol 23:297-311

Bibiloni MA, Uriz MJ, Gili JM (1989) Sponge communities in three submarine caves of the Balearic Islands (Western Mediterranean): adaptations and faunistic composition. PSZN Mar Ecol 10:317-334

Boury-Esnault N (1971) Spongiaires de la zone rocheuse de Banyuls-sur-mer. I. Ecologie et repartition. Vie Milieu 22:159-192

Castillejo FF, Esteban AE, Lavín A (1984) Medidas de corrientes en la bahía de Santander y zona adyacente por medio de flotadores. Bol Inst Esp Oceanogr 1:79-93

Castric-Fey A, Girard-Descatoire A, L'Hardy-Halos M-Th, Derrien-Coutel S (2001) La vie sous-marine en Bretagne. Découverte des fonds rocheux. Biotope (eds), Cahiers Naturalistes de Bretagne, Region Bretagne

Díaz MC, Alvarez B, Laughlin RA (1990) The sponge fauna on a fringing coral reef in Venezuela II Community structure. In: Rützler K (ed) New perspectives in sponge biology. Smithsonian Institute Press, Washington, pp 367-375

Dunlap M, Pawlik JR (1996) Video-monitored predation by Caribbean reef fishes on an array of mangrove and reef sponges. Mar Biol 126:117-123

García-Castrillo G, Rodríguez C, Puente A, Preciado I, Serrano A, Juanes J (2000a) Cartografiado bentónico sublitoral de la isla de Mouro (Cantabria). Ozeanografika 3:69-83

García-Castrillo G, Serrano A, Preciado I, Rodríguez C, Puente A, Juanes J (2000b) Estructuración biocenótica de la comunidad submareal de laminariales de la isla de Mouro (Mar Cantábrico, Santander). Ozeanografika 3:85-99 
Ghiold J, Rountree GA, Smith SH (1994) Common sponges of the Cayman Islands. In: Brunt MA, Davies JE (eds) The Cayman Islands natural history and biogeography. Kluwer Academic Publishers, Dordrecht, pp 131-138

Harmelin J-G (1985) Organisation spatiale des communautés sessiles des grottes sous-marines de Méditerranée. Rapp Commun Int Mer Médit 29:149-153

Hartnoll RG (1983) Substratum. In: Earl R, Erwin DG (eds) Sublittoral ecology. The ecology of the shallow sublittoral benthos. Clarendon Press, Oxford, pp97-124

Hiscock K (1991) Benthic marine ecosystems in Great Britain: a review of current knowledge. Nat Conserv Council 1170:1-94

Jokiel PL (1980) Solar ultraviolet radiation and coral reef epifauna. Science 207:1069-1071

Kitching JA, Macan TT, Gilson HC (1934) Studies in sublittoral ecology. I. A submarine gulley in Wembury Bay, S. Devon. J Mar Biol Ass UK 19:677-705

Laubenfels MW (1950) An ecological discussion of the sponges of Bermuda. Trans Zool Soc Lond 27:155-201

Maldonado M, Uriz MJ (1995) Biotic affinities in a transitional zone between the Atlantic and the Mediterranean: a biogeographical approach based on sponges. J Biogeogr 22:89-110

Maldonado M, Uriz MJ (1999) An experimental approach to the ecological significance of microhabitat-scale movement in an encrusting sponge. Mar Ecol Prog Ser 185:239-255

Maldonado M, Young CM (1996) Bathymetric patterns of sponge distribution on the Bahamian slope. Deep-Sea Res 43:897-915

Pansini M (1987) Littoral demosponges from the banks of the Strait of Sicily and the Alboran Sea. In: Vacelet J, BouryEsnault N (eds) Taxonomy of porifera, Vol G13. NATO ASI series, pp149-185

Pérès JM, Picard J (1964) Nouveau manuel de bionomie bentique de la Mer Méditerranée. Recl Trav Stn Mar Endoume Fac Sci Mars 31:5-137
Preciado I (2002) Demosponjas litorales del entorno de la isla de Mouro: taxonomía y ecología. PhD thesis, Universidad Autónoma de Madrid, Madrid

Puente A (2000) Distribución y estructura de las comunidades de macroalgas de la isla de Mouro (Cantabria, Golfo de Vizcaya). Consideraciones sobre su aplicación en la vigilancia ambiental de espacios litorales. PhD thesis, Universidad de Cantabria, Santander

Rützler K, Díaz MC, Van Soest RWM, Zea S, Smith KP, Álvarez B, Wulff J (2000) Diversity of sponge fauna in mangrove ponds, Pelican Cays, Belize. Atoll Res Bull 476:231-248

Sarà M, Vacelet J (1973) Ecologie des démosponges. In: Grassé PP (ed) Traité de Zoologie. Anatomie, systématiqué, biologie. Vol III. Spongiaires. Masson et Cie, Paris, pp462-576

Schmahl GP (1990) Community structure and ecology of sponges associated with four Southern Florida coral reefs. In: Rützler K (ed) New perspectives in sponge biology. Smithsonian Institution Press, London, pp 376-383

Templado J, Guerra A, Bedoya J, Moreno D, Remón JM Maldonado M, Ramos MA (1993) Fauna marina circalitoral del sur de la península Ibérica. Resultados de la Campaña Oceanográfica "Fauna I". Museo Nacional de Ciencias Naturales, Consejo Superior de Investigaciones Científicas

Uriz MJ, Rosell D, Martín D (1992) The sponge population of the Cabrera Archipelago (Balearic Islands): characteristics, distribution and abundance of the most representative species. PSZN Mar Ecol 13:101-117

Vacelet J (1976) Les spongiaires des grottes sous-marines obscures de la Méditerranée et des régions tropicales. PSZN Mar Ecol 40:506-515

Witman JD, Sebens KP (1990) Distribution and ecology of sponges at a subtidal rock ledge in the Central Gulf of Maine. In: Rützler K (ed) New perspectives in sponge biology. Smithsonian Institution Press, London, pp391-396 